\title{
Divulgação Científica no combate às Fake News em tempos de Covid-19
}

\section{Scientific Dissemination in the fight against Fake News in the Covid-19 times \\ Difusión Científica en la lucha contra las Noticias Falsas en la era Covid-19}

Recebido: 21/05/2020 | Revisado: 26/05/2020 | Aceito: 28/05/2020 | Publicado: 14/06/2020

\section{Luiz Felipe Santoro Dantas}

ORCID: https://orcid.org/0000-0001-9713-4432

Instituto Federal de Educação, Ciência e Tecnologia do Rio de Janeiro, Brasil

E-mail: santoro.luizfelipe@gmail.com

Eline Deccache-Maia

ORCID: https://orcid.org/0000-0003-4770-3988

Instituto Federal de Educação, Ciência e Tecnologia do Rio de Janeiro, Brasil

E-mail: eline.maia@ifrj.edu.br

\section{Resumo}

Neste momento em que o mundo foi acometido pela Covid-19, o número de notícias falsas (fake news) que circulam diariamente nos meios de comunicações vem influenciando grande parte da população, tornando imprescindível a discussão sobre o papel da ciência atualmente. Esse quadro coloca em evidência a importância da Divulgação Científica como apoio ao movimento de Alfabetização Científica, que pode vir a permitir uma maior identificação de notícias sem fundamentos. A Divulgação Científica, desde os primeiros esforços rumo as suas práticas, mantem estreito diálogo com a Alfabetização Científica e contribui no combate do "obscurantismo beligerante", termo criado por Newton Duarte (2018), e da pseudociência que se alastra por diversas mídias sociais, alimentada pelas fake news. É por meio da democratização cultural da ciência que se oportunizará um melhor discernimento daquilo que é importante para que se tenha um acesso à saúde, à cidadania e ao engajamento político. Dessa maneira, por se tratar de um tema recente e de extrema importância, este trabalho de cunho exploratório, apoiado na pesquisa bibliográfica, tem por objetivo reunir e apresentar pontos relevantes no papel da Divulgação Científica que podem auxiliar na diminuição do impacto das fake news.

Palavras-chave: Divulgação científica; Covid-19; Fake News. 


\section{Abstract}

At a time when the world was affected by Covid-19, the number of fake news that circulate daily in the media has been influencing a large part of the population, making the discussion about the role of Science currently indispensable. This table highlights the importance of Scientific Dissemination as a support for the scientific literacy movement, which may allow a greater identification of unfounded news. The scientific dissemination since the first efforts towards their practices keeps a close dialogue with scientific literacy and contributes to the fight against "belligerent obscurantism", a term created by Newton Duarte (2018) and the pseudoscience that spreads through several social media, fueled by fake news. It is through the cultural democratization of science that a better understanding of what is important for access to health, citizenship and political engagement will be provided. Thus, as it is a recent and extremely important topic, this exploratory work, supported by bibliographic research, aims to gather and present relevant points in the role of Scientific Dissemination that can help to reduce the impact of fake news.

Keywords: Scientific dissemination; Covid-19; Fake News.

\section{Resumen}

En un momento en que el mundo se vio afectado por Covid-19, la cantidad de noticias falsas que circulan diariamente en los medios de comunicación ha influido en gran parte de la población, lo que hace que la discusión sobre el papel de la ciencia sea actualmente indispensable. Esta tabla resalta la importancia de la divulgación científica como un apoyo para el movimiento de alfabetización científica, que puede permitir una mayor identificación de noticias sin fundamento. La difusión científica desde los primeros esfuerzos hacia sus prácticas mantiene un diálogo cercano con la Alfabetización científica y contribuye a la lucha contra el "oscurantismo beligerante", un término creado por Newton Duarte (2018) y la pseudociencia que se propaga a través de varias redes sociales, impulsada por la falsificación Noticias. Es a través de la democratización cultural de la ciencia que se proporcionará una mejor comprensión de lo que es importante para el acceso a la salud, la ciudadanía y el compromiso político. Por lo tanto, como es un tema reciente y extremadamente importante, este trabajo exploratorio, apoyado por la investigación bibliográfica, tiene como objetivo reunir y presentar puntos relevantes en el papel de la divulgación científica que pueden ayudar a reducir el impacto de las noticias falsas.

Palabras clave: Difusión científica; Covid-19; Fake News. 


\section{Introdução}

A doença causada pelo agente etiológico SARS-CoV-2, denominada de Covid-19, é oriunda, como tudo tem indicado, de Wuhan (China), tendo se espalhado rapidamente no final de 2019 por muitos países da Ásia e de demais regiões do mundo todo, ocasionando uma pandemia. A Covid-19 apresenta um quadro clínico de febre, tosse, falta de ar e, em casos mais graves, pneumonia, síndrome respiratória aguda, insuficiência renal, podendo levar a óbito (Bertolini, 2020). De acordo com a Organização Mundial de Saúde - OMS (2020), cerca de $80 \%$ dos casos podem ser assintomáticos, cerca de $20 \%$ podem requerer atendimento hospitalar e, desses casos, aproximadamente 5\% podem necessitar de suporte ventilatório para o tratamento de insuficiência respiratória.

A pandemia de Covid-19 representa um desafio para a manutenção da saúde humana global, não muito diferente de outros desafios já vivenciados, mas com proporções drásticas devido a seu alto grau de disseminação. Segundo Song \& Karoko (2020), o compartilhamento rápido de informações científicas é uma maneira eficaz de reduzir o pânico e o contágio do público pela Covid-19, sendo uma ação chave para fornecer orientação em tempo real aos epidemiologistas que trabalham para conter o surto. Porém, ao mesmo tempo em que o compartilhamento de notícias elaboradas a partir de fontes seguras pode amenizar e contribuir para a população entender e melhor se proteger dessa nova doença, a enxurrada de notícias falsas, intituladas de fake news, que circulam diariamente contribuem para a desinformação que leva ao descuido, fazendo tão mal à saúde da população quanto a doença em si, deixandoa cada vez mais vulnerável.

Pennycook et al. (2020), em pesquisa de combate à desinformação da Covid-19 nas mídias sociais com cidadãos americanos, constataram que as fake news podem levar as pessoas a recorrerem a remédios ineficazes e que podem ser prejudiciais. Fake news podem, ainda, levar ao exagero de certas reações que induzem ao acúmulo de mercadorias e muitas vezes até ações mais perigosas como desenvolver um comportamento de risco e espalhar inadvertidamente o vírus.

Uma das possibilidades de se combater as fakes news e deixar a população menos vulnerável é estimular um maior diálogo entre a ciência e a população. Podemos atingir esse objetivo com atividades de Divulgação Científica, cujo propósito é estender o acesso aos conhecimentos científicos produzidos, estimulando o senso crítico e a Alfabetização Científica do público em geral. Por exemplo, nos últimos anos tem surgido youtubers de ciência que produzem material dinâmico de Divulgação Científica; um nome que se destacou 
recentemente por causa da pandemia do covid-19 é o do microbiologista Átila Iamarino.

O presente artigo parte do princípio de que a Divulgação Científica possui importante potencial para o enfrentamento do grave quadro de saúde pública que enfrentamos. Dessa maneira, através de um breve histórico, definições e contribuições da Divulgação Científica para a população em geral, o objetivo deste trabalho é reunir e apresentar alguns pontos relevantes que podem colaborar para responder a seguinte pergunta: "Qual o papel da Divulgação Científica nos tempos de pandemia causada pela Covid-19?” e, em decorrência “Como a Divulgação Científica pode auxiliar na diminuição do impacto das fake news?

\section{Metodologia}

Pelo cenário imposto pela pandemia da Covid-19 e por ser um tema recente, este é um trabalho fundado em abordagem qualitativa, de caráter exploratório, apoiado na pesquisa do tipo bibliográfica realizada por meio de um levantamento de livros, dissertações, teses e artigos científicos nacionais e internacionais, principalmente na área de Divulgação Científica e de ensino. Segundo Gil (2008, p. 50),

A principal vantagem da pesquisa bibliográfica reside no fato de permitir ao investigador a cobertura de uma gama de fenômenos muito mais ampla do que aquela que poderia pesquisar diretamente. Esta vantagem se torna particularmente importante quando o problema de pesquisa requer dados muito dispersos pelo espaço.

A coleta dos documentos iniciou-se a partir de buscas em sites de revistas na área de ensino e educação e através da plataforma google scholar ${ }^{1}$ com o objetivo de delimitar as produções acerca da Divulgação Científica e sobre a disseminação de notícias falsas no âmbito nacional e internacional. Para o suporte das definições e histórico do assunto e da importância da Alfabetização Científica realizou-se uma busca em livros que tratavam desses assuntos e de teses e dissertações através do portal da CAPES sobre a história e definições a respeito do assunto investigado.

Em relação à discussão e visando retratar os assuntos atuais da pandemia do novo coronavírus e o tema fake news foi realizada busca em sites internacionais como, por exemplo, o da Organização Mundial da Saúde (Word Heath Organization) e de sites

\footnotetext{
${ }^{1} \mathrm{O}$ google scholar é uma ferramenta de pesquisa do Google que permite pesquisar em trabalhos acadêmicos, literatura escolar, jornais de universidades e artigos variados. Pode ser acessado no link: https://scholar.google.com
} 
nacionais como o do Ministério da Saúde. Após o esforço realizado pelo levantamento dos dados foi dado início à compilação dos mesmos e a sua análise.

\section{A Divulgação Científica e Alfabetização Científica}

Agora mais do que nunca precisamos falar sobre ciência. Em tempos de pandemia notícias oriundas de fontes não fidedignas se propagam e põem em xeque o impacto da educação científica que não tem conseguido produzir leitores críticos suficientes, capazes de separar o "joio do trigo". Poderíamos dizer que parte significativa da população reconhece a ciência, mas não identifica no seu discurso conexão com a sua realidade, além de não compreender os seus fundamentos, não tendo intimidade com esse tipo de atividade. Nesse aspecto, a Divulgação Científica surge como possibilidade de ponte entre a população e a ciência, levando à comunidade as produções e estudos feitos pelos cientistas por meio de linguagem mais acessível.

A Divulgação Científica é entendida por pesquisadores que se propõem a estudar esse fenômeno como um movimento que visa traduzir a produção do conhecimento científico para a população com pouco ou nenhum acesso a esse universo (Souza, 2011; Albagli, 1996). Indo na mesma direção, Gouvêa (2015. p.17) define o processo de Divulgação Científica como

A divulgação da ciência e da técnica é uma prática social realizada em diversos contextos educativos que envolve sempre uma reelaboração do discurso científico e de alguma forma algum processo de aculturação, pois, além dos conhecimentos, são apresentados os pensamentos da cultura científica.

A Divulgação Científica vai muito além de uma tradução ou reelaboração de uma linguagem científica, está relacionada ao processo de democratização cultural de uma sociedade, na qual a cultura científica restrita a um pequeno grupo tem a possibilidade de se disseminar por toda sociedade, levando essas informações para os mais diversos grupos sociais. Concordamos com Messeder Neto (2019, p.19) ao dizer que

É preciso destacar que o trabalho de divulgação da ciência não é um favor que a academia ou outros centros de pesquisa fazem à população em geral, ela é uma obrigação visto que a produção do conhecimento só é possível graças ao trabalho diário de homens e mulheres que na sociedade de classe ainda não adentram o espaço acadêmico. Na impossibilidade desses sujeitos participarem diretamente do processo de produção dos saberes científicos e de conhecerem sua linguagem, é essencial que os cientistas coloquem a divulgação como sendo um elemento ético e imprescindível do seu próprio fazer ciência. A divulgação científica tem como obrigação mostrar para a 
população os produtos e processos da ciência, tendo compromisso com a objetividade e com a fidedignidade do objeto que está sendo apresentado.

Para o nosso cenário de pesquisa é indispensável que se discuta a Alfabetização Científica, compreendida como um processo de construção de entendimento no qual o indivíduo adquiri capacidade para analisar e avaliar situações que permitam a tomada de decisões e o posicionamento diante de questões relevantes para ele e que envolvam a necessidade da compreensão da ciência (Sasseron, 2015). Segundo Chassot (2003), Alfabetização Científica é saber ler a linguagem em que está escrita a natureza, bem como utilizar essa linguagem para potencializar o entendimento da natureza e transformar as necessidades em algo melhor, utilizando a ciência para a defesa da natureza e da vida em toda sociedade.

Tendo em vista que a sociedade utiliza tecnologia e ciência diariamente, é necessário que se tenha um discernimento mínimo daquilo que é importante para o acesso à cidadania, à melhor qualidade de vida, poder vir a ter preocupações ambientais e algum engajamento político, entre outros. Assim, o processo que estimula a Alfabetização Científica visa potencializar nossa leitura de mundo, formando sujeitos capacitados para tomada de decisões no meio social, político e econômico (Costa, 2008). O estudo dos conceitos científicos são aspectos essenciais que vão além da percepção do pensamento do mundo científico e tecnológico, eles permitem compreender e participar das decisões sócio-políticas.

Vale destacar que ser alfabetizado cientificamente não significa entender todo conhecimento científico, até porque seria impossível. Ser alfabetizado em ciência significa ter o mínimo de conhecimento necessário para poder avaliar os avanços da ciência e tecnologia e suas implicações na sociedade e ambiente (Dantas, 2016). É relevante estar atento às mudanças do mundo científico, ou seja, conhecer o que está sendo desenvolvido para questionar suas consequências imediatas e no futuro.

\section{Um Panorama Histórico sobre a Divulgação Científica}

Compreender o histórico da Divulgação Científica nos ajuda a explicar diversas iniciativas ao longo do tempo e suas mudanças geradas por contexto científico, político e econômico em cada época e lugar. Esse entendimento atualmente se torna extremante necessário para um melhor esclarecimento em toda sociedade, sobretudo nestes dias em que assistimos a uma crescente discussão entre saúde - ciência - política. 
Mueller \& Caribé (2010) destacam que o progresso da imprensa móvel de Gutenberg no final do século XV permitiu o acesso ao conhecimento de mais pessoas, contribuindo para a Divulgação Científica. Vale ressaltar que até então as publicações eram escritas majoritariamente em Latim, língua utilizada pelas poucas pessoas letradas na Europa daquele período. Percebe-se, então, que o conhecimento ficava restrito apenas a um pequeno círculo de iniciados que dominavam essa língua, constituindo uma elite intelectual.

Os textos de cunho científico se tornaram mais acessíveis quando os filósofos e estudiosos abandonaram a língua do latim erudito e começaram a escrever em línguas vernáculas, nos séculos XVI e XVII (Mueller \& Caribé, 2010). De acordo com Souza (2008) e Albagli (1996), o início da Divulgação Científica ocorreu com a "Revolução Científica" dos séculos XVI e XVII, trazendo um novo panorama de compreensão e interpretação dos seus resultados, incentivando os avanços da ciência. Ainda no século XVII, as academias de ciência espalharam-se pela Europa, com intuito de uma comunicação aberta e oral sobre itens científicos através de reuniões. É nessa mesma época que apareceram os primeiros periódicos científicos e as pioneiras publicações e movimentos de Divulgação Científica (Mueler \& Caribé, 2010).

Até esse momento nota-se que a Divulgação Científica fica restrita a um grupo privilegiado. Porém, no final do século XVIII, com a Revolução Industrial, os avanços tecnológicos em prol das atividades industriais proporcionaram um movimento para um processo de Divulgação Científica mais abrangente, como indica Silva (2006, p.54),

Já no século XVIII anfiteatros europeus enchiam-se de um público ávido por conhecer novas máquinas e demonstrações de fenômenos pneumáticos, elétricos e mecânicos, apenas para citar alguns exemplos. Algumas exposições e palestras, relacionadas à física, à química ou à medicina, eram itinerantes, percorrendo diversas cidades e, às vezes, diversos países.

Ainda de acordo com Silva (2006), essas exposições e palestras eram atividades de Divulgação Científica produzidas como verdadeiros espetáculos científicos, pensados para atrair audiência. Nesses eventos eram utilizados instrumentos científicos como microscópios, telescópios, instrumentos magnéticos para facilitar a demonstração de conceitos e com o objetivo de reter a atenção do público com entretenimento (Mueler \& Caribé, 2010). A ideia de demonstração já se desenhava como aspecto facilitador do entendimento dos conceitos científicos.

Em paralelo, foi também no século XVIII que surgiram os primeiros livros de Divulgação Científica destinados a um público irrestrito e leigo, abordando praticamente 
todas as áreas da ciência (Mueler \& Caribé, 2010; Silva, 2006). Museus e centros de ciências também se constituíram importantes espaços de divulgação científica que ganharam maior expressão do século XIX em diante. Também no século XIX foram publicados os primeiros periódicos científicos como a Nature em 1869 e a Science em 1880.

Nessa mesma época, o Brasil também estava caminhando, ainda que lentamente, para um processo de difusão científica. De acordo com Moreira \& Massarani (2012), algumas iniciativas nessa direção surgiram, sobretudo com a chegada da Corte Portuguesa no Brasil em 1808, fazendo com que a produção científica e a sua divulgação ganhassem maior fôlego. A permissão para impressão fora da metrópole foi importante na produção de textos e manuais voltados para a educação científica, que começaram a ser produzidos com a criação da Imprensa Régia, em 1810 (Moreira \& Massarini, 2012).

As novas teorias e descobertas científicas começaram a ser veiculadas no Brasil de modo mais dinâmico a partir de 1874, quando a ligação telegráfica do Brasil por meio de cabo submarino foi feita com a Europa. Assim, os jornais da época começaram a divulgar essas informações e o país pôde acompanhar e se informar sobre os avanços científicos (Moreira \& Massarini, 2012). Entre os séculos XIX e XX a forma de se divulgar a ciência foi revolucionada pelas tecnologias da comunicação; como exemplo podemos citar a invenção e propagação do rádio, TV e internet.

Não muito diferente do que ocorreu na Europa, aqui no Brasil, ainda que em menor escala, assistimos à produção de diversos livros voltados à Divulgação Científica e algumas coleções científicas. Em 1979, apareceram os primeiros programas de TV com programações científicas, como, por exemplo, o Nossa Ciência (com apenas dez emissões) e o programa Globo Ciência, que está no ar desde 1984. Diversas revistas de Divulgação Científica foram produzidas no país como a Revista Ciência Hoje (1982), Superinteressante (1987) e a Globo Ciência (1991), rebatizada como Galileu em 1998, além do surgimento do jornalismo científico (Moreira e Massarini, 2012; Mueler \& Caribé, 2010; Albagli, 1996).

Ainda que seja possível perceber que a partir da década de 1980 tivemos um incremento nos equipamentos e materiais de divulgação científica, ainda nos ressentimos de não termos um público consumidor significativo que possa fazer frente às várias fake news existentes. Um público consumidor de muitos desses veículos de informação necessita de um mínimo de Alfabetização Científica, por mais simples que sua linguagem seja, para poder avaliar seu conteúdo. 


\section{A Divulgação Científica no Contexto Atual}

As tecnologias de informação e comunicação (TIC) sempre foram importantes parceiras no processo de Divulgação Científica, mas nos últimos séculos têm sido fundamentais para a nossa sociedade. Por meio de suas múltiplas formas foi possível entrarmos em contato com a produção de conhecimento no mundo. Para Ponte (2000), as TIC têm acarretado uma revolução em várias profissões e atividades: na investigação científica, nos processos de ensino/aprendizagem, no jornalismo, na prática médica, nas empresas, na administração pública, entre outras. A facilidade e a agilidade que a tecnologia pode representar e processar qualquer tipo de informação é um dos fatores determinantes para tal fato. Pereira \& Silva (2010), relatam que a evolução das TIC não provocou mudanças apenas nas áreas de tecnologia e comunicação, mas em diversas áreas do conhecimento humano. As TIC foram responsáveis por alterações na conduta, nos costumes, no consumo, no lazer, nas relações entre os indivíduos e nas formas como eles se comunicam.

Quando falamos das novas TIC não podemos esquecer a internet, uma das mais intensas e desconcertantes invenções dos últimos tempos que tornou possível apresentar o mundo como em uma vitrine, nos permitindo mirar as múltiplas produções humanas. $\mathrm{O}$ surgimento da internet possibilitou à sociedade o acesso imediato a todo tipo de informações e serviços através das redes de computadores, smartphones e tablets, em escala global, possibilitando difundir e democratizar todo e qualquer tipo de informação, por meio da captura de tela, armazenamento de conteúdo, pesquisas diversas, além de ferramentas tecnológicas que nos permitem analisar, avaliar e transformar essas informações em conhecimento (Leite, 2011).

Apesar de todos os benefícios que a internet pode trazer em termos de Divulgação Científica, tornando informações acessíveis de maneira instantânea, precisamos ser cautelosos. Nem tudo que circula pela rede é produzido com o mesmo princípio da ciência. A ciência, ao menos a boa ciência, segue protocolos que visam produzir um discurso embasado, possível de ser construído pelo uso de métodos e procedimentos que visam à busca da fidedignidade com a realidade. Não é só a ciência que produz discurso fidedigno, mas a ciência o tem como pressuposto. Contudo, nem sempre o que cai na rede é embasado em dados e fatos. Muitos conteúdos são pobres em evidências, contudo a influência de uma publicação, notícia em redes sociais e a sua replicação pode converter uma mentira em uma "verdade absoluta", como é o caso das muitas fake news, colocando por terra o adágio popular de que "a mentira tem perna curta". Esse aspecto torna a internet um espaço onde podemos 
encontrar tanto coisas boas como ruins, assim como no mundo concreto, cabendo ao receptor conseguir discernir.

Desde o início da descoberta do novo coronavírus, no final de 2019, até ser declarada pela Organização Mundial da Saúde como pandemia em 11 de março de 2020, devido à rápida disseminação geográfica, é possível citar inúmeras discussões sobre a cura da Covid19 que circulam nas redes sociais, aplicativos de mensagens e páginas na internet. Podemos identificar desde receitas caseiras para o combate ao vírus e utilização de remédios sem comprovações científicas até ações que movimentam pessoas para uma corrida de compra de mercadorias de todos os tipos.

No "Canal Saúde Sem Fake News"2 do Ministério da Saúde já são mais de 100 notícias $^{3}$, especificamente sobre a Covid-19, relatando se o material informativo que circula na internet é cientificamente embasado ou fake news. Foi possível encontrar notícias como: "Chá de limão com bicarbonato quente cura coronavírus", "Beber água de 15 em 15 minutos cura o coronavírus", "Máscaras de doação da China são contaminadas com coronavírus", "Remédio de piolho pode matar coronavírus" etc. Esses são apenas alguns exemplos de fake news que se espalham em todos os tipos de redes sociais, podendo levar as pessoas a acreditarem nessas informações e desacreditarem na ciência e, o que é pior, fazer com que as pessoas acreditem que esta é uma doença com fácil tratamento e que não mata.

Percebemos que uma informação mal elaborada ou até mesmo mal utilizada tem o poder de prejudicar/depreciar a percepção pública da ciência, ainda mais em ambientes onde quase toda a população tem acesso às redes sociais (Nascimento, 2012). Contudo, pode-se constatar o potencial indispensável que as novas tecnologias de informação e comunicação têm no contexto social e acadêmico, pois, além de proporcionarem a Divulgação Científica através do uso e recuperação das informações, facilitam as trocas entre a sociedade e o pesquisador, além de viabilizarem a comunicação entre os pesquisadores, facilitando a troca de informações e permitindo, assim, um fluxo dinâmico e contínuo.

\footnotetext{
${ }^{2}$ O Canal Saúde Sem Fake News do Ministério da Saúde. O Canal foi criado em agosto de 2018 com o intuito de desmentir notícias falsas que circulam na internet. Qualquer cidadão poderá enviar gratuitamente mensagens com imagens ou textos que tenha recebido nas redes sociais para confirmar se a informação procede, antes de continuar compartilhando. Atualmente o canal tem uma aba específica direcionando os usurários para notícias apenas sobre a Covid-19 podendo ser acessada através do site: https://www.saude.gov.br/fakenews/

${ }^{3}$ A consulta à plataforma "Canal Saúde Sem Fake News" foi realizada em 19 de maio de 2020.
} 


\section{A Ciência e as Fake News}

Mais do que nunca cientistas, professores, divulgadores científicos, independente da área a que pertencem e atuam, precisam se juntar para combater essa quantidade de fake news, usando os mais diferentes meios como vídeos, textos, podcasts, respeitando o isolamento social. A contribuição da Divulgação Científica em tornar a ciência mais acessível ao público leigo, conta hoje com um grande desafio que é o de despertar em parcela significativa da população o interesse em ter contato com seus conteúdos. Segundo Messeder Neto (2019, p.20):

Não cabe mais aos divulgadores apenas apresentar o conhecimento científico à população, é preciso ir para o confronto, mostrando as fragilidades das pseudociências, dos mitos, das fake news, e das religiões. Trata-se não apenas de mostrar o que está certo, mas de desmentir informações que circulam diuturnamente como se fossem verdades.

Para além da sinalização de que alguns conteúdos disseminados são falsos e solicitação de não compartilhamento, é preciso mostrar o que move pessoas e/ou grupos a criarem as fake news. Um dado observado nesta época de pandemia é a grande quantidade de notícias falsas sobre certos alimentos que combatem a Covid-19, usando referências com citações, fontes e cientistas falsos, buscando utilizar os mesmos critérios que a ciência usa ao explicitar a origem de seus dados, demonstrando que suas pesquisas partem de fontes seguras e confiáveis. Tal movimento busca chancelar uma pseudociência que simula fundamentação teórica e científica. Em alguns casos as fake news tomam como base pesquisas que ainda estão sendo desenvolvidas, propalando resultados inconclusivos e/ou controvérsias como sendo resultados definitivos. É o caso da cloroquina, medicamento originalmente usado contra a malária e que vem sendo estudado para o combate do coronavírus, não tendo as pesquisas sobre o tema chegado a uma conclusão razoável.

Uma fake news que ocasionou grandes problemas foi veiculada pelo presidente dos Estados Unidos da América Donald Trump, no dia 23 de abril de 2020, sugerindo o uso de desinfetantes para o tratamento da Covid-19, afirmação feita sem nenhum fundamento científico. Segundo informação do jornal DailyNews ${ }^{4}$, números extraordinariamente alto de nova-iorquinos entrou em contato com as autoridades de saúde da cidade por medo de ter ingerido alvejante ou outros produtos de limpeza nas 18 horas que se seguiram à falsa

\footnotetext{
4 Reportagem consultada no site https://www.nydailynews.com/coronavirus/ny-coronavirus-new-yorkershousehold-cleaners-trump-20200425-rnaqio5dyfeaxmthxx2vktqa5m-story.html.
} 
(CC BY 4.0) | ISSN 2525-3409 | DOI: http://dx.doi.org/10.33448/rsd-v9i7.4776

informação dada pelo presidente Trump de que injetar tais produtos poderia curar o coronavírus. Ao ser questionado por jornalistas sobre a declaração, Trump disse que estava sendo apenas "sarcástico". Esse exemplo demonstra como uma notícia falsa pode ser nefasta, tendo efeito intensificado quando a mensagem é transmitida por alguém que conta com a credibilidade de parte da população.

Newton Duarte (2018) destaca que nas últimas décadas há um avanço do fenômeno ideológico e político de direita em todo mundo que vem resultando naquilo que o autor denominou "obscurantismo beligerante". Esse fenômeno ataca tudo que possa ser ameaçador às posições ideológicas preconceituosas e conservadoras contra o conhecimento e a razão, utilizando diversas estratégias, sendo as mais radicais aquelas de propagação de ódio a qualquer pensamento ou comportamento considerado contrários as suas ideias, sendo as suas fontes taxadas de "esquerdismo", “comunismo" ou "imorais" (Duarte, 2018).

O obscurantismo em si não é fato novo, no entanto ele toma uma dimensão avassaladora nos dias atuais pela velocidade com que as fake news se propagam e pelos discursos de ódio produzidos e disseminados diariamente nos ambientes digitais. Como aponta Newton Duarte (2018, p.139),

O obscurantismo beligerante não é um fenômeno novo. Em 1964, às vésperas do golpe que instaurou a ditadura, vários setores representativos das forças de direita organizaram no Brasil movimentos com características de obscurantismo beligerante. $\mathrm{Na}$ atualidade esse fenômeno se apresenta, porém, com algumas peculiaridades, entre as quais pode-se assinalar que o mundo virtual da internet mostrou-se um terreno favorável para ataques extremamente violentos, caluniosos e sem qualquer respaldo na objetividade dos fatos. Em outras palavras, o obscurantismo é o maior beneficiário das "fake news".

Esse ambiente difícil de hostilidade reforça a ideia de que é preciso mais do que nunca divulgar a ciência, combater os pseudocientistas que desinformam e destroem a educação científica. A forma como muitas fake news são divulgadas, fazendo uso de fontes pseudocientíficas, dificulta a identificação, por grande parte da população, da falta de respaldo e da inverdade que encobre a má fé por trás dos seus conteúdos. Não há como garantir que a recepção dessas mensagens seja no sentido da crença cega, mas o aumento de atividades de Divulgação Científica pode criar um público mais atento e exigente com os conteúdos, sabendo minimamente identificar aquilo que vale a pena ser lido.

Nas redes sociais, onde há uma circulação maior das fake news, as empresas como Twitter, Facebook e Instagram estão adotando medidas para evitar que essas informações se espalhem, buscando amenizar os impactos de conteúdos pouco confiáveis e proteger, 
minimamente, a vida das pessoas. O Twitter, por exemplo, anunciou uma série de mudanças em suas regras de moderação para remover as mensagens falsas que possam colocar as pessoas em risco de contrair a Covid-19. Dentre os critérios adotados para retiradas automáticas das mensagens estão a negação de fatos científicos, manipulação de dados, medidas de proteção e descrição ineficazes e prejudiciais.

O Facebook e o Instagram direcionam os usuários para informações oficiais quando se procura informações sobre a Covid-19. Porém, no WhatsApp as informações circulam livremente e sem nenhum tipo de filtro, além disso nem sempre recebemos informações por redes sociais, o que torna a circulação de fake news um fenômeno de difícil controle. Por esse motivo se faz muito necessário que o receptor das mensagens tenha condições de verificar suas fontes através de sites oficiais, como o do Ministério da Saúde pelo portal "Canal Saúde Sem Fake News" ou de sites oficiais como da Organização Mundial de Saúde. Os passos colocados na Tabela 1, apresentados a seguir, auxiliam nesse processo de decisão dos indivíduos de identificar as fake news. 
Tabela 1. Como identificar as fake News.

\section{Passos para identificar fake news}

\section{1 - Avalie a fonte, o site, o autor do conteúdo}

Muitos sites publicadores de fake news têm nomes parecidos com endereços de sites de notícias.

Portanto, avalie o endereço e verifique se o site é confiável. Veja se outros conteúdos do site também são duvidosos.

\section{2 - Avalie a estrutura do texto}

Sites que divulgam fake news costumam apresentar erros de português, de formatação, letras em caixa alta e uso exagerado de pontuação.

\section{3 - Preste atenção na data da publicação}

Veja se a notícia ainda é relevante e está atualizada.

\section{4 - Leia mais que só o título e o subtítulo}

Leia a notícia até o fim. Muitas vezes o título e o subtítulo não condizem com o texto.

\section{5 - Pesquise em outros sites de conteúdo}

Duvide se você receber uma notícia bombástica que não esteja em outros sites de notícia.

\section{6 - Veja se não se trata de site de piadas}

Alguns sites de humor usam da ironia para fazer piada.

\section{7 - Só compartilhe após checar se a informação é correta}

Não compartilhe conteúdo por impulso. Você é responsável pelo que você compartilha.

Fonte: Adaptado da Apresentação Fake News relacionadas à saúde: como identificar e combater? ${ }^{5}$

\section{Considerações Finais}

A crescente discussão e debate entre saúde e ciência que a Covid-19 vem impondo na atualidade sinaliza a importância de fazer chegar até a população conteúdos científicos. No entanto, não basta apenas fazer chegar esses conteúdos se a população não tiver uma formação mínima que permita o seu consumo consciente.

\footnotetext{
${ }^{5}$ A Tabela 1 é uma adaptação da apresentação "Fake News relacionadas à saúde: como identificar e combater?" feita pelo diretor da Assessoria de Comunicação Social, Ugo Braga no VIII Congresso Brasileiro de Enfermagem Pediátrica e Neonatal (CBEPN), realizado no período de 15 a 18 de outubro de 2019. Recuperada de http://portalarquivos.saude.gov.br/campanhas/arquivos/fake_news.pptx
} 
Desse modo, ao resgatar uma das perguntas que nortearam este trabalho, "Qual o papel da Divulgação Científica nos tempos de pandemia causada pela Covid-19?”, observamos que a Divulgação Científica se apresenta como importante propiciador de um maior senso crítico da realidade tornando a população menos vulnerável às fake news, que se espalham com uma rapidez incontrolável e deixam a população assustada, como é o caso das notícias falsas sobre a pandemia da Covid-19.

Em relação à segunda pergunta, "Como a Divulgação Cientifica pode auxiliar na diminuição do impacto das fake news?", antes de tudo devemos nos atentar para um aspecto que marca este período da nossa história que é a necessidade do isolamento social, a fim de minimizar os efeitos da pandemia. Assim, as atividades de Divulgação Científica devem ser no sentido de preservar as pessoas e sua necessidade de isolamento. Portanto, o material criado precisa chegar até o público que está em casa, circulando nos mesmos veículos das fake news, ou seja, via redes sociais e plataformas existentes na internet, por meio da produção de podcasts, vídeos, lives etc. O importante é saber que as pessoas que elaboram conteúdos de Divulgação Científica estão preocupadas com a linguagem usada e na produção de conteúdos que exerçam atração em um público que é constantemente bombardeado por uma plêiade de materiais originados de diversas fontes.

Democratizar a ciência e levá-la para toda população pode oportunizar um melhor discernimento daquilo que é importante para que se tenha acesso à saúde, à cidadania e ao engajamento político. Esse é o papel da Divulgação Científica: auxiliar na promoção da Alfabetização Científica e combater a pseudociência por trás das fake news, enfraquecendo as ideias propagadas e, por conseguinte, diluindo o impacto de tendências do "obscurantismo beligerante" que marca a atualidade.

Por fim, ratificamos a importância de um número maior de trabalhos e produções de Divulgação Científica apresentando a ciência de uma maneira mais acolhedora, aberta a todos e criando leitores que possam se defender não só da doença, mas, neste momento, das mentiras em torno dela.

\section{Referências}

Albagli, S. (1996). Divulgação científica: Informação científica para cidadania. Ciência da Informação, 25(3), 396-404. 
Bertolini, D. (2020). Covid-19. Sociedade Brasileira de Análise Clínicas - SBAC. Recuperado em maio, 2020, de http://www.sbac.org.br/blog/2020/04/06/covid-19/

Chassot, A. (2003). Alfabetização científica: uma possibilidade para a inclusão social. Revista Brasileira de Educação. (22), 89-100. doi: 10.1590/S1413-24782003000100009

Costa, L. P. (2008). Alfabetização Científica: A sua importância na Educação de Jovens e Adultos. Educação \& Tecnologia. 13(2).

Dantas, L. F. S. (2016) Desenvolvimento de aplicativo gratuito de busca para a divulgação de centros e museus ciência do estado do Rio de Janeiro. (Dissertação de Mestrado Profissional em Ensino de Ciências da Natureza). Universidade Federal Fluminense, Niterói / RJ. Recuperado de https://app.uff.br/riuff/handle/1/4808

Duarte, N. (2018). O currículo em tempos de obscurantismo beligerante. Revista Espaço do Currículo, 2(11). doi: 10.22478/ufpb.1983-1579.2018v2n11.39568

Gil, AC (2008). Métodos e técnicas de pesquisa social. 6 ed. São Paulo: Atlas.

Gouvêa, G. (2015). A Divulgação da Ciência, da Técnica e Cidadania e a Sala de Aula. In: Santos, MG \& Cunha, MB. Divulgação Científica na Sala de Aula: Perspectivas e Possibilidades. 1.ed. São Paulo: Unijui.

Leite, B. S. (2015). Tecnologias no Ensino de Química: Teoria e prática na formação docente. 1.ed. Curitiba: Appris Ltda.

Moreira, I. C \& Massarani, L. (2002). Aspectos Históricos da divulgação científica no Brasil. In: Massarani, L, Moreira, IC \& Brito, F. (Org). Ciência e Público: Caminhos da divulgação científica no Brasil. 1.ed. Rio de Janeiro: Editora UFRJ. Recuperado de http://www.museudavida.fiocruz.br/images/Publicacoes_Educacao/PDFs/cienciaepublico.pdf

Mueller, S. P. M \& Caribé, R. C. V. (2010). A comunicação científica para o público leigo: breve histórico. Informação \& Informação, 15(1), 13-30. doi: 10.5433/19818920.2010v15n1espp13 
Messeder Neto, H. S. (2019). A Divulgação Científica em tempos de obscurantismo e de fake news: contribuições histórico-críticas. In: Rocha, MB \& Oliveira, RDVL. (Org.). Divulgação Científica: Textos E Contextos, 1.ed. São Paulo: Livraria da Física.

Organização Mundial de Saúde - OMS. (2020). Advice for public. Recuperado de https://www.who.int/emergencies/diseases/novel-coronavirus-2019/advice-for-public

Pennycook, G, McPhetres, J, Zhang, Y. \& Rand, D. (2020). Fighting COVID-19 misinformation on social media: Experimental evidence for a scalable accuracy nudge intervention. PsyArXiv, (preprints), 1-24. doi: 10.31234/osf.io/uhbk9

Pereira, D. \& Silva, G. (2010). As Tecnologias de Informação e Comunicação (TICs) como aliadas para o desenvolvimento. Caderno de Ciências Sociais Aplicadas, (8), 151-174. Recuperado de http://periodicos2.uesb.br/index.php/ccsa/article/view/1935

Ponte, J. P. (2000). Tecnologias de informação e comunicação na formação de professores: Que desafios? Revista Ibero-Americana de Educación, (24), 63-90. doi: 10.35362/rie240997

Sasseron, L. H. (2015). Alfabetização científica, ensino por investigação e argumentação: relações entre ciências da natureza e escola. Ensino Pesquisa Educação em Ciências. 17(esp), 49-67. doi: 10.1590/1983-2117201517s04

Silva, H. C. (2006). O que é divulgação científica? Ciência \& Ensino, 1(1), 53-59. Recuperado de http://200.133.218.118:3535/ojs/index.php/cienciaeensino/article/download/39/98

Song, P \& Karako, T. (2020). COVID-19: Real-time dissemination of scientific information to fight a public health emergency of international concern. BioScience Trends, 14(1),1-4. doi: 10.5582/bst.2020.01056.

Souza, A. V. S. (2008). A Ciência Mora Aqui: Reflexões Acerca dos Museus e Centros de Ciência Interativos do Brasil. (Dissertação de Mestrado em História das Ciências e das Técnicas e Epistemologia). Universidade Federal do Rio de Janeiro / RJ. Recuperado de http://www.casadaciencia.ufrj.br/Publicacoes/Dissertacoes/adriana_dissertacao.pdf 
Research, Society and Development, v. 9, n. 7, e797974776, 2020

(CC BY 4.0) | ISSN 2525-3409 | DOI: http://dx.doi.org/10.33448/rsd-v9i7.4776

Porcentagem de contribuição de cada autor no manuscrito

Luiz Felipe Santoro Dantas - 60\%

Eline Deccache-Maia - 40\% 